Orleans and other cities that lack many of our sanitary advantages."

The Army engineers in charge of the water supply are aware of the defects in the system, and have excellent plans for remedying them; but money is required to carry them to completion. Dr. Smart closed by urging the expenditure.

"Think of the 75 deaths from typhoid fever annually in every 100,000 of the population, 60 deaths more than in the city of Brooklyn, and more than we would have in this city if our water was as pure as that of Brooklyn. Putting our population at a quarter of a million, we have 150 unnecessary deaths every year. Ah! but the cases! To find the number of cases we must multiply the deaths by twenty! Three thousand cases of serious sickness, each lasting from two to six weeks. Three thousand cases of disease that might be prevented by the expenditure of a little money. Think of the suffering, anxiety and sorrow involved in the history of these three thousand cases, and then say whether an appropriation having in view the purification of the city water supply is a good investment or a bad one."

\section{DESCENT OF THE TESTICLE IN ADULT LIFE} BY ALBER'T H. TUTTLE, M.D.

CAMBRIDGE, MASS.

As such cases as the following must be of extreme rarity, and as they shed a great amount of light on the phenomena of earlier and normal descent, and at the same time perhaps instruct us somewhat as to the manner in which we should deal with cases of undescended testicle; cases where the majority of opinion has been in favor of the complete removal of the organ when it interferes with the comfort of the patient, is caught in the inguinal rings, or complicates a hernia, I have deemed this instance one worthy of consideration.

Not long ago I operated for strangulated hernia complicated with undescended testicle, and after closing the hernial sac and rings, drew the testicle, which was enclosed in the sac, into the scrotum and fastened it there with the tunica by means of stitches. This procedure necessitated the invagination in part of the scrotum. The result was perfect, but after the operation the gentlemen present, some four members of the profession, expressed as their opinion that I should have sacrificed the testicle, and questioned the result. When they said such testicles do not prove of much practical value, I could only answer that I had been consulted by patients with one undescended testicle who were willing to undergo a surgical operation in order to satiate their desire for a second testicle in the scrotum. They simply echoed the general opinion of the profession. But the time has come when we must deal more rationally with these cases, and it is already heralded by various reports in our latest journals.

E. W. L., aged 31 years, was born with a congenital hernia on the right side and an undescended testicle on the left. He wore a truss on the right side until 12 years old; it was then discarded until the age of 21 , when he put on a double truss and wore it until six months ago; since, he has employed simply a suspensory bandage to keep the bowel in place.

I saw him for the first time about two years ago; an examination showed an absence of the left testicle, and a dilated condition of the inguinal rings on both sides. In the standing position the abdominal wall bulged outward at the site of the rings, and an impulse was felt on coughing.
It was obvious that the sac was not a great one, and that the gut at that time would not descend far along the cord, although it had at an earlier date, according to the statement of the patient. He consulted me for an attack of gonorrhea at this time, and informed me that he had had a similar attack some six years previous. During his first attack he had a swollen testicle on the right side and sharp pain deep in the left groin. Since, he has had a swollen testicle on the right side without any apparent cause. I recognized the condition of the patient at the first visit, and recommended an operation for the radical cure of the herniæ.

He went to Europe shortly afterwards, and I saw nothing of him until a few weeks ago. I now find the testicle on the left side of the scrotum, the inguinal rings smaller than when I first examined them, and, without artificial support, the gut does not distend the abdominal wall or give an impulse on coughing to the contents of the scrotum. The patient experiences no discomfort without the trusa, and only about once a week a "limp" appears in the left groin "in the evening when the muscles are tired ;" this disappears on lying down, or on pressure.

The following history of the descent of the testicle is given in the words of the patient as nearly as possible: About a year and three months ago a skin, like a bag full of water, came down, and kept getting larger toward evening; the bag became about egg.size, and could be emptied by pressure; in about three months-a year ago-he was sitting writing a letter in the evening, when something was suddenly felt below (in the scrotum); he looked and found the testicle had come down. It disappeared the same evening, but returned to the scrotum a week later, when he tied it down with a piece of tape. In this manner he kept it down for a week; it then returned to the abdomen, and remained concealed three days, and when it came down stayed longer. It has kept going up and coming down, each time staying longer in its normal condition, until now it has remained in the scrotum for about four months.

When the "bag of water" first appeared, it made the scrotum red and hot and somewhat uncomfortable; it disappeared during the night, and on lying down.

He has been married for about one year. Since the attack of gonorrhea two years ago, he has had at times bloody urethral discharges with the seminal ejections, or immediately after intercourse. Examination by the microscope shows nothing abnormal in the seminal fluid except the presence of blood, which probably mixes with it somewhere in the genital tract, external to the testicle. This bloody discharge, for which he recently consulted me, is a complication of the old gonorrhea, and in my opinion has nothing to do with the lately descended testicle.

It seems possible that by care this case will obtain a spontaneous cure of the herniæ.

\section{TRACHOMA.}

Read before the South Kansas Medical Society at Wichita, Kan., Nov. 21, 1893 .

BY FLAVEL B. TIFFANY, M.D.

PROFESSOR OF OPHTHALMOLOGY IN THE UNIYERSITY MEDICAL COLLEGE OF KANSAS CITY, MO.; OCULIST TO GRKMAN AND ALL SAINTS HOSPITALS, ETC.

Trachoma (from the Greek $\tau \rho \alpha \chi v \zeta$, rough), is the term intended to designate a certain disease of the lining of the lids or palpebral conjunctiva; but it has been so indiscriminately used by physicians and some oculists when speaking of the different forms of conjunctivitis that there is much confusion as to its real signification. To most physicians, it means any form of granular conjunctivitis, be it simple, acute, subacute or chronic; especially if there is much roughness of the lining of the lids. In acute conjunctivitis we have a swelling of the papillæ, giving a very rough condition of the palpebral mucous membrane, but this is not trachoma.

In catarrhal ophthalmia, and especially in purulent ophthalmia, the papillæ swell enormously, also the different glands, those of Moll and the Meibomian as well as the trachoma glands; but again, this is not trachoma. Inflammation of the conjunctiva may pass through the different stages, from simple 